\title{
Dinámicas energéticas e integración regional en el noroeste argentino y el sur boliviano ${ }^{1}$
}

\author{
Silvina Cecilia Carrizo ${ }^{2}$ y Didier Ramousse ${ }^{3}$
}

\begin{abstract}
RESUMEN
En el noroeste de Argentina y el sur de Bolivia estos países comparten una cuenca rica en gas, recurso energético demandado en el norte de Chile. Esta región transfronteriza se ha encontrado históricamente complicada en su relación con los proyectos nacionales y en las posibilidades de autonomía de sus territorios. En el largo plazo, el estudio de sus dinámicas energéticas y de la integración regional muestran las disputas político-económicas que alientan y frenan alternativamente la producción de hidrocarburos. Actualmente, los Estados nacionales procuran regular la actividad petrolera e intentan acotar el poder de las empresas extranjeras. Por su parte, los gobiernos locales buscan aumentar sus beneficios en la actividad y favorecer las inversiones. Luego se refuerzan las relaciones entre gobiernos locales y una constelación de actores dominada por empresas privadas transnacionales. El juego histórico entre poderes públicos locales y nacionales con poderosos actores privados, acrecienta la vulnerabilidad de estos territorios fronterizos y sociedades marginadas que sufren de los vaivenes en la explotación de sus recursos naturales.
\end{abstract}

Palabras clave: Energía, integración, territorio.

\begin{abstract}
The Northwest of Argentina and the South of Bolivia share a gas-rich basin, an energetic resource highly valued by the North of Chile. This limiting region has had historical complications regarding its relation to national projects and possibilities of territorial autonomy. In the long term, the study of energetic dynamics and regional integration reveals the political-economic disputes that encourage and restrain hydrocarbon production alternatively. At the moment, national States seek the regulation of oil activity to limit the power of foreign companies. On their part, local governments are trying to increase their benefits from hydrocarbon related activity and to favour investments. Because of this, relations between local governments and an array of actors, dominated by transnational companies, are reinforced. The historical relationship between local and national public powers with powerful private actors increases the vulnerability of these marginal territories and societies that suffer the consequences of exploitation of their natural resources.
\end{abstract}

Key words: Energy, integration, territory.

1 Artículo recibido el 12 de junio de 2009 y aceptado el 31 de agosto de 2009.

2 Centro de Estudios Urbanos y Regionales, Consejo Nacional de Investigaciones Científicas y Técnicas (Argentina). E-mail: scarrizo@conicet.gov.ar
3 Centre d'Economie et d'Ethique pour I'Environnement et le Développement (C3ED), Université de Versailles Saint-Quentin en Yvelines (Francia). E-mail: didier. ramousse@wanadoo.fr 
En el noroeste de Argentina y el sur de Bolivia, los territorios -históricamente imbricados- tienen una relación compleja con los proyectos nacionales y en su autonomía. Ambos países comparten en la región una cuenca rica en gas que reagrupa tierras nororientales de la provincia de Salta y los departamentos de Tarija, Chuquisaca y Santa Cruz. Sus yacimientos resultan aún más atractivos por su ubicación estratégica para servir al norte de Chile y el sur de Brasil. Operadores internacionales se instalaron a ambos lados de la frontera y compiten por la explotación de los recursos desde antaño. En distintos momentos históricos, las empresas privadas impulsaron la interconexión petrolera y gasífera, proyectos que aparecen en la primera y segunda década del siglo XX y cuyos avances estuvieron marcados fundamentalmente por los cursos de las políticas nacionales. Las dinámicas energéticas e integración regional, desde hace más de un siglo, suscitan disputas que alientan y frenan alternadamente la producción de hidrocarburos.

Las empresas privadas han encontrado una resistencia recurrente a su expansión irrestricta en el piedemonte andino, en buena medida por la fricción generada en los juegos de poder entre las provincias del noroeste argentino y la Nación, o entre países de la región, compitiendo a veces por el desarrollo de sus proyectos. Una diversidad de actores aparece buscando sortear, resolver o mitigar los conflictos que surgen en los procesos de integración que muchas veces ellos mismos revelan y realzan. A menudo se trata de organizaciones no gubernamentales, actores privados, otros niveles de actores públicos (gobiernos locales y provinciales), entes regionales y organismos internacionales que hacen prevalecer enfoques sectoriales pragmáticos como los ecológicos, agroindustriales o energéticos.

Este artículo ilustra las dinámicas energéticas y la integración regional, a través del análisis de la interconexión de las redes de hidrocarburos de Argentina y Bolivia, en una región conectada también al norte chileno. El análisis no apunta a un inventario descriptivo de los recursos o de las infraestructuras, sino que se fundamenta en distintos enfoques relacionados con los juegos de actores involucrados en la explotación de los recursos energéticos, los procesos de gobernanza multiniveles (regional, nacional, transnacional) y el desarrollo de los territorios (Crozet \& Musso, 2003). Se trata de caracterizar las redes energéticas y sus cambios de función de su (dis)funcionamiento en un espacio transnacional, refiriéndose a los modos de articulación entre los actores, sus actividades y los territorios donde operan (Dupuy, 1988). Las modalidades de gestión de las redes se han vuelto cada vez más complejas por la intervención e interacción de un número creciente de actores. Concomitantemente, se multiplican los ámbitos de negociación, de decisión y de regulación a escalas local y regional de modo complementario o antagónico con los niveles nacionales, así como también se reproducen sobre la escena internacional a través de acuerdos binacionales o regionales (Scheer, 2007). Frente a las incertidumbres generadas por un entorno cambiante en América Latina (Lagos, 2008), es grande la tentación de un repliegue nacional o la búsqueda de otras alternativas fuera del ámbito regional.

Este texto está estructurado en cuatro partes. En la primera, se trata la recurrencia de conflictos en la integración de esta región transfronteriza a los espacios nacionales y en su autonomía respecto de ellos. En la segunda, se presentan las configuraciones de actores y los cambios en sus estrategias, a partir de las reformas en la década de 1990 y las contrarreformas del sector petrolero en Argentina y Bolivia, en los años 2000. En la tercera sección se abordan las nuevas dinámicas hidrocarburíferas a nivel local. Finalmente el cuarto apartado está referido a los cambios en los procesos de integración gasífera en función de las nuevas preocupaciones energéticas.

\section{La confrontación recurrente entre intereses públicos y privados}

En la segunda mitad del siglo XIX se intentó la explotación de hidrocarburos en el noroeste argentino. Las provincias de Salta y Jujuy emprendieron exploraciones, obtuvieron resultados positivos y otorgaron concesiones a empresas privadas: a la Compañía Jujeña del Kerosene, en 1865, y a Altgelt y 
Méndez en 1882. Luego se harían otras exploraciones, descubrimientos y desarrollos a través de iniciativas nacionales, como la expedición al Chaco del geólogo Luis Brackebusch de la Universidad de Córdoba, entre 1884 y 1885 , por encargo del Ministerio del Interior en 1881, y privadas, como la de Francisco Tobar en 1906. Dichas iniciativas concluyeron en fracasos comerciales, técnicos o geológicos (YPF, 2000), pero tempranamente daban cuenta de la existencia de hidrocarburos en la región.

Al igual que en la actualidad, en aquel entonces las minas eran propiedad de la Nación o las provincias, según el territorio donde se encontraran. Cuando en 1907 la División de Minas, Geología e Hidrología del Ministerio de Agricultura de la Nación descubre petróleo en el territorio nacional patagónico, la legislación vigente no autorizaba al Estado a explotar minas. Por ende, el presidente Figueroa Alcorta decretó la creación de una reserva de 10.000 ha, como un área especial donde el Estado pudiese explorar y explotar el subsuelo. En el Congreso aprobaron una reserva de 5.000 ha. Entre los legisladores, algunos apoyaban y otros se oponían al Estado empresario, y en ambos grupos había quienes avalaban la actividad privada en el sector petrolero, regulada en función de los intereses nacionales, sosteniendo que su aporte podía ser significativo para la economía del país, como lo era en ferrocarriles, telecomunicaciones, puertos, electricidad y otros servicios. A partir de ese evento comenzaría la organización formal de la producción nacional de hidrocarburos. En el noroeste argentino, la División de Minas Geología e Hidrología de la Nación emprendió estudios y perforaciones que aportaron al conocimiento de la región, como los relevamientos realizados en 1911, por el geólogo Guido Bonarelli (gerente de exploración de Yacimientos Petrolíferos Fiscales (YPF) 19221928), entre otros.

Las empresas privadas fueron explorando el potencial de las regiones. Entre las compañías extranjeras instaladas en la región, Standard Oil of New Jersey fue la que tuvo mayor trascendencia. Se posicionó en el sur boliviano y en el norte argentino (provincias de Salta y Jujuy) en la década de 1920. En corto tiempo, descubrió petróleo en Bolivia, en las proximidades del río Bermejo, límite político entre los dos países. Este hallazgo estimuló la exploración sobre la margen argentina, donde se dio el descubrimiento de Aguas Blancas en 1926 (Figura $N^{\circ}$ 1) y luego Lomitas, Cerro Tartagal, Ramos y San Pedro -este último muy importante- (YPF, 2000).

Para la misma época, la empresa petrolera nacional YPF -fundada en 1922- conseguiría que Salta y Jujuy le concediesen un área y que no autorizasen nuevos permisos. En contrapartida, pagaría regalías del $10 \%$ y cedería infraestructura (Gadano, 2006). YPF tendría dificultades (jurídicas y técnicas) para comenzar a operar en el área, no obstante, procuraba que se aumentase la extensión de la superficie que tenía otorgada en el norte de Argentina (ratificada por el Poder Ejecutivo salteño en 1929) e intentaba impedir que la Standard Oil acumulara áreas mientras permaneciese pendiente la sanción de la Ley Nacional de petróleo. Si bien Salta y Jujuy obraban a favor de YPF, lo hacían en la medida en que favorecer la estrategia nacional no perjudicara los intereses económicos provinciales. Por un lado, rechazaban excluir a las empresas privadas que invertían y generaban ingresos; por otro, buscaban obtener de YPF beneficios mayores.

Tras el derrocamiento del presidente Hipólito Yrigoyen (1916-1922, 1928-1930) -favorable a una política petrolera nacional-, el gobierno de facto del general Uriburu (1930-1932) no se mostró contrario a YPF. En 1931, autorizó un acuerdo entre la provincia de Salta e YPF por el cual esta podría explotar una reserva de tierras contra el pago de regalías del $13 \%$ y la cesión de infraestructura (Gadano, 2006). YPF acotaba así el posicionamiento de la Standard Oil que, por su lado, consiguió no ser desalojada y continuar produciendo petróleo. Aunque a un ritmo menor que las empresas privadas, YPF pudo expandirse en el norte. A nivel nacional, YPF también fue aumentando su producción, pero con un progresivo retroceso del peso nacional en el sector (Solberg, 1979). La Standard Oil, cuya actividad crecía a ambos lados de la frontera, solicitó al gobierno federal (la provincia de Salta estaba intervenida) autorización para construir un oleoducto desde Bolivia hasta Manuel Elordi (Salta), donde tenía depósitos y una refinería. YPF se opuso 
a que la empresa dispusiese de tal posibilidad por considerarlo desfavorable a los intereses nacionales (Gadano, 2006).

Poco después de la derrota frente a Paraguay en la Guerra del Chaco (1932-1935), el Estado boliviano creó la empresa Yacimientos Petrolíferos Fiscales Bolivianos (YPFB) por medio del Decreto Ley del 21 de diciembre de 1936, nacionalizó la actividad petrolera y expropió a la Standard Oil (indemnizada en 1942). Entonces YPFB quedó a cargo de la exploración, explotación y evacuación de los hidrocarburos en todo el territorio de Bolivia. La relación entre YPF boliviana e YPF argentina fue fluida, con apoyo técnico e intercambios de personal. Hacia 1950, con perforadoras nuevas que permitían alcanzar mayor profundidad, hicieron descubrimientos importantes en la región, como Campo Durán en 1951 y Madrejones en 1954 (Figura $\mathrm{N}^{\circ} 1$ ).

Pero a cada lado de la frontera las empresas nacionales encontraron obstáculos naturales, económicos y políticos. Los presidentes argentinos Juan Domingo Perón (1946-1952, 1952-1955) y Arturo Frondizi (1958-1962), primero favorables a la actividad nacional, terminaron apoyando la actividad privada. Los presidentes bolivianos Víctor Paz Estenssoro (1952-1956) y Hernán Siles Suazo (1956-1960) también favorecerían la inversión privada extranjera.

En 1960 la refinería de YPF en Campo Durán (provincia de Salta) quedaba vinculada por un poliducto de $1.480 \mathrm{~km}$ con la refinería San Lorenzo de YPF (provincia de Santa Fe) y por un gasoducto de $1.700 \mathrm{~km}$ con Buenos Aires. Esa infraestructura facilitaba también la evacuación de hidrocarburos bolivianos. Por entonces, la refinería de Cochabamba proveía gas líquido de petróleo a ese departamento y al de Santa Cruz donde se haría una unidad de producción la década siguiente, precisamente en Camiri. Con el argumento de que la exportación directa de gas a Argentina era perjudicial para el país, en 1969, se ejecutó la segunda nacionalización petrolera en Bolivia (Figura $N^{\circ} 1$ ).

En su primer gobierno, el presidente boliviano Hugo Banzer (de facto 1971-1978; constitucional 1997-2001) reabrió la entrada a las empresas privadas extranjeras. En los años 1990, tanto Argentina como Bolivia se plegarían a las corrientes privatizadoras y desreguladoras dejando a los Estados fuera de la actividad hidrocarburífera. Esto cambiaría en los primeros años del siglo XXI. Bajo el gobierno del presidente argentino Néstor Kirchner (2003-2007) se creó Energía Argentina Sociedad Anónima (ENARSA, Ley 25.943/ 2004). En el año 2005, el actual presidente boliviano, Evo Morales, concretaría la tercera nacionalización. Pero en estas instancias de reinserción de los Estados en la actividad hidrocarburífera, en ninguno de los dos países excluyeron a las empresas privadas.

\section{La distribución de ingresos públicos y la contención de las inversiones privadas}

En Argentina, la política general energética es definida por el Estado federal. No obstante, en $1992^{1}$ las provincias recuperaron la propiedad de los recursos hidrocarburíferos que se encuentran en sus subsuelos y pasaron, con la ley corta de 2006, a estar facultadas para aplicar las directrices energéticas, establecer lineamientos particulares y ejercer el control de la actividad (solicitar auditorías de reservas y ambientales, verificar el cumplimiento del plan de inversiones y adoptar sanciones). Fundamentalmente, pueden licitar bloques y otorgar concesiones de exploración y explotación. El Estado nacional, a través de la empresa ENARSA, puede hacer lo propio en la plataforma marítima continental, cuyo dominio le corresponde.

En Bolivia, en el año 2005 (Ley 3.058), siguiendo la voluntad popular expresada por referéndum en 2004, el Estado recuperó la propiedad de los hidrocarburos; se refundó YPFB (Yacimientos Petrolíferos Fiscales Bolivianos) y se transformaron los contratos de "riesgo compartido" (Ley 1.689 de 1996) en contratos de "producción compartida, operación o asociación", con la entrega de la totalidad de los hidrocarburos producidos a YPFB. El 50\% más una de las acciones de las empresas Chaco S. A., Andina S. A., Transredes S. A., Petrobrás Bolivia Refinación S. A. y Compañía Logística de Hidrocarburos de Bolivia S. A. pasaron a YPFB (Decreto 28.701/2006). 
Figura $\mathrm{N}^{0} 1$

Redes de hidrocarburos en el noroeste argentino y Bolivia

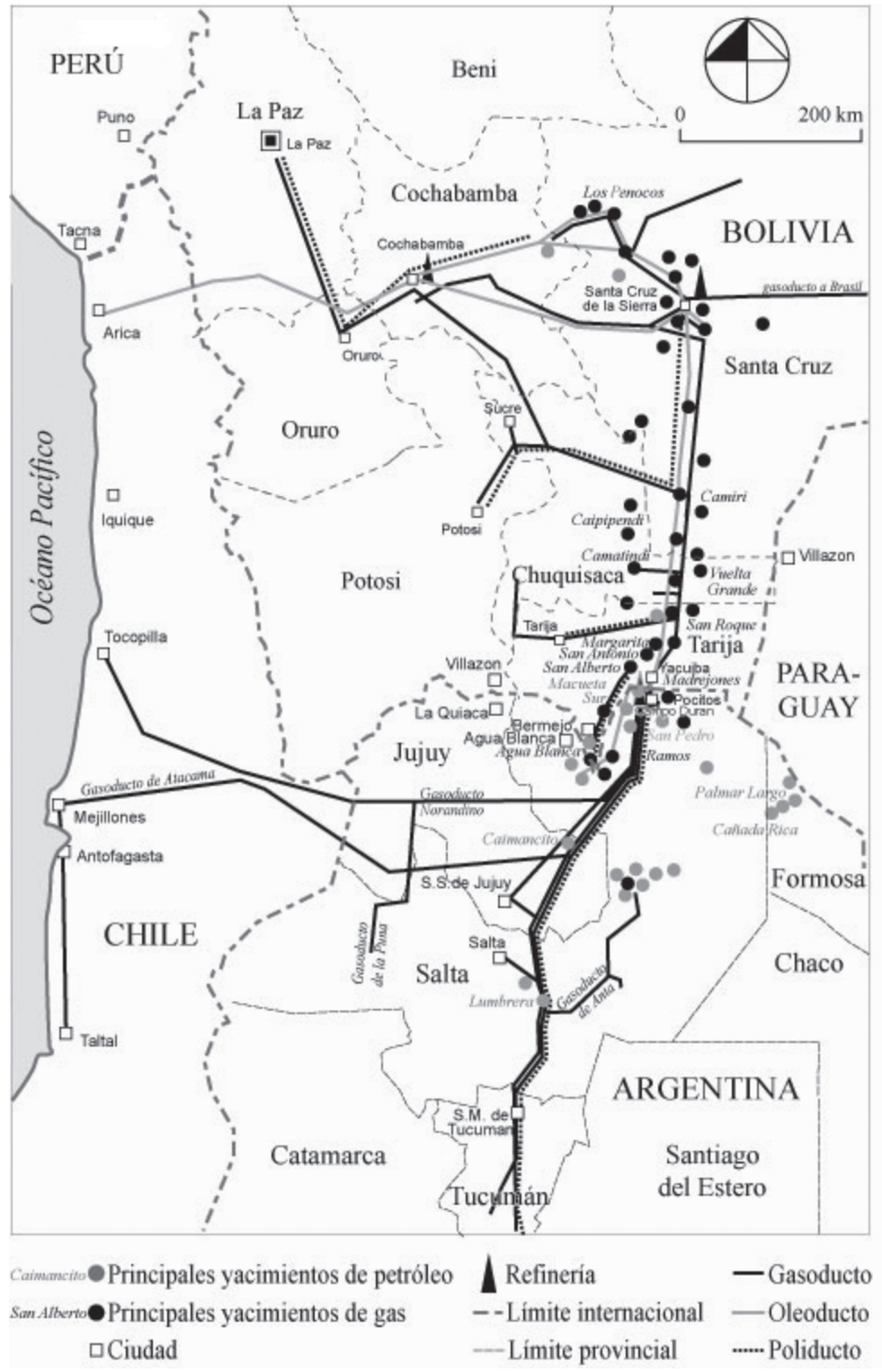

Fuente: Elaboración propia. 
Chaco era la sociedad British Petroleum y Bridas, operando en Bolivia (Panamerican Energy en Argentina). Andina nació en 1996 con la capitalización de YPFB y era de ex empleados de YPFB (2\%), de AFP (48\%) y de Repsol YPF (50\%) que obtuvo acciones de las argentinas YPF, Perez Companc y Pluspetrol. Transredes era una empresa transportadora de gas también nacida con la capitalización de YPFB, propiedad de Ashmore Energy Internacional (50\% comprado a TR Holdings de Enron y Shell), AFP (34\%) y otros (16\%). Las empresas petroleras en upstream aceptaron las nuevas condiciones del Estado boliviano para permanecer en esas áreas con reservas probadas y continuar la extracción en los yacimientos. Transredes no acuerda y, por ende, YPFB pasa a controlar un $98 \%$ de la empresa. Petrobrás fue indemnizada por las refinerías que fueron nacionalizadas completamente.

Tanto las provincias productoras argentinas -y la Nación por las áreas offshore en zona de su jurisdicción- como los departamentos productores bolivianos, perciben regalías por los hidrocarburos extraídos de sus subsuelos (del $12 \%$ y $11 \%$, respectivamente). Del lado argentino, puesto que los recursos pertenecen a las provincias, estas podrían modificar el porcentaje que perciben en concepto de regalías, que ha sido de $12 \%$ desde que la Nación se las otorgara en compensación por los hidrocarburos extraídos de sus subsuelos y cuyo dominio había adquirido. Por ejemplo, Chubut y Mendoza han buscado reducir el porcentaje cobrado por regalías para atraer inversiones en zonas complicadas, mientras que Neuquén evalúa aumentarlo para concesiones de zonas atractivas. Del lado argentino, la Nación cobra además un monto móvil como retenciones a la exportación de hidrocarburos (Resolución 394/2007). Del lado boliviano, el Estado recupera en total $82 \%$ del valor de la producción: $18 \%$ en regalías (11\% para departamentos productores, $6 \%$ para el Tesoro General de la Nación y $1 \%$ a título compensatorio para los departamentos de Beni y Pando por Ley $3.058 / 2005) ; 32 \%$ para YPFB y $32 \%$ para el IDH (Impuesto Directo sobre Hidrocarburos). Los departamentos productores bolivianos recuperan $12,5 \%$ del IDH, mientras el Tesoro General de la Nación cobra 56,25\% y los departamentos no productores $31,25 \%$ (Decreto 28.421/2005). Los departamentos productores del oriente del país reivindican la posibilidad de controlar efectivamente su repartición y en Tarija y Santa Cruz piden la propiedad de los hidrocarburos, además de una parte más importante de la renta.

Las regalías cobradas en el año 2008, en el noroeste argentino entre las provincias de Salta, Jujuy y Formosa, representaron un ingreso de más de 171 millones de dólares, casi en su totalidad percibidos en Salta, por la explotación de su gas (170 millones de dólares que representan $15 \%$ del total del país). Los ingresos por hidrocarburos permitieron que el gobierno provincial de Salta impulsara una estrategia de oferta energética como atractivo para las actividades productivas, basada en el tendido de los gasoductos:

1. Se construyó el gasoducto de la Puna (67 millones de dólares, $185 \mathrm{~km}$ ) para facilitar la reactivación minera (en el año 2008, la provincia produjo $360 \mathrm{mil}$ toneladas de minerales -fundamentalmente boratosque se exportan principalmente a Brasil, China y Estados Unidos).

2. Se tendió el gasoducto de Anta (79 millones de dólares, $235 \mathrm{~km}$ ) para estimular la producción agroindustrial (granos, oleaginosas, citrus, hortalizas).

3. Se licitó el proyecto del gasoducto de los Valles Calchaquíes para suministrar gas a agroindustrias y a pequeñas localidades, pero necesitó un nuevo llamado a licitación.

El gasoducto de la Puna provee 2 millones $\mathrm{m}^{3} / \mathrm{mes}$. Derivado del gasoducto de Atacama construido para la exportación a Chile, abastece mayormente tres empresas de producción de litio, ácido bórico y azufre. El de Anta comienza su puesta en marcha con unos 600 millones de $\mathrm{m}^{3} /$ mes, aprovisionando una planta de cítricos y próximamente una acopiadora de granos. Con el gasoducto de la Puna se instaló un servicio de emergencia vial (SOS), o sea que esas obras permiten disponer de energía para hacer viables emprendimientos productivos en lugares aislados, a la vez que abren camino a otros sistemas de comunicación y conexión. Los gasoductos quedan bajo la administración de la empresa provincial REMSA creada por la provincia 
de Salta para administrar sus pertenencias mineras. A través de REMSA, la provincia busca involucrarse en todas las áreas de la energía: transporte de gas y distribución, administración de áreas de hidrocarburos libres, generación solar y transporte eléctrico, comunicaciones.

En Bolivia, el $80 \%$ de las reservas de gas se ubican en el departamento de Tarija. Los ingresos por la actividad hidrocarburífera permitieron a Tarija ampliar los servicios públicos de gas -contando ahora con más del $32 \%$ de los usuarios del país- y de electricidad, a partir de generación local, por no estar conectado al sistema interconectado nacional. El 66,99\% del ingreso por el IDH se reparte entre los municipios en función del número de habitantes; $8,62 \%$ se destina a la universidad pública del departamento y el resto a la prefectura (Decreto 29.322/2007).

Argentina y Bolivia necesitan avanzar en el desarrollo de sus cuencas, tanto por el ingreso económico que la producción de hidrocarburos genera a los Estados y la región, como por la importancia de los mismos en las matrices energéticas. En Argentina es necesario explorar para encontrar reservas que remonten los horizontes de actividad y especialmente compensen la paulatina disminución de la producción de su mayor yacimiento gasífero, Loma La Lata (cuenca de Neuquén), que produce unos 21 millones $\mathrm{m}^{3 /}$ día. En Bolivia, las empresas aprovechan la máxima capacidad instalada para responder a las demandas internas y de Argentina y Brasil, pero las operaciones se ven afectadas por conflictos en los departamentos del oriente boliviano -Tarija, Beni, Pando, Santa Cruzque reclaman autonomía para obtener capacidad de decisión y administración. Luego los proyectos de exploración y desarrollo en que las compañías extranjeras venían invirtiendo y sus búsquedas agresivas de nuevos mercados se han paralizado.

La contención de las inversiones privadas en la región puede deberse, en cierta medi$\mathrm{da}$, a la prudencia del sector privado frente a riesgos político-económicos que se perciben en cada país y a la ausencia de seguridad jurídica; los procesos burocráticos que implican la aplicación de las nuevas reglas de juego establecidas por los gobiernos o demo- ras en las administraciones pueden contribuir también a frenar las inversiones. Para compensar esta situación y mejorar los niveles de producción, los Estados promueven alianzas con otros países o crean alicientes para las empresas del sector. En Argentina, ENARSA firma acuerdos estratégicos con otras empresas nacionales como Petrobrás (Brasil), Petrouruguay (Uruguay), Sipetrol (Chile) e YPF (Argentina) y abre un concurso (ronda 1 en agosto 2008) para explorar áreas costa afuera. A su vez, varias provincias productoras de hidrocarburos (Salta, Chubut, La Pampa, Mendoza, Neuquén, Río Negro, Santa Cruz) y otras que buscan serlo (San Luis, La Rioja, San Juan) han licitado áreas de exploración y/o desarrollo costa adentro. En Bolivia, el Estado privilegia nuevos acuerdos con compañías estatales como PDVSA Petróleos de Venezuela, Gazprom o la compañía iraní NIOC.

En el noroeste argentino, el gobierno de Salta hizo esfuerzos para promover la reposición de reservas en disminución e impulsó la licitación de nuevos bloques en 2007, buscando revertir el estancamiento de la producción de gas y de petróleo en la provincia en los últimos años. En el área Acambuco, Pan American Energy -joint-venture entre British Petroleum $(60 \%)$ y la empresa argentina Bridas (40\%) - trabaja asociada a las empresas Shell (22,5\%), Repsol YPF (22,5\%), Apco $(2,5 \%)$ y Norwest $(2,5 \%)$. Sus yacimientos San Pedrito y Macueta - descubiertos por YPF y PAE, respectivamente- producen 4,5 millones de $\mathrm{m}^{3} /$ día en alta presión cada uno y compensan el declive de la producción de gas natural del noroeste. La Dirección Provincial de Minería y Recursos Energéticos de la provincia de Jujuy confirmó que licitará doce áreas.

\section{Redes hidrocarburíferas en lenta expansión}

Actualmente Argentina y Bolivia encuentran dificultades para incrementar la producción de hidrocarburos y la inyección de gas en las redes. Agrandar la capacidad de transporte estimularía desarrollar y aumentar las reservas de gas, pero los proyectos de construir nuevos gasoductos se ven desalentados por el nivel insuficiente de producción. Esta situación circular frena las inversiones y la 
multiplicación de los intercambios gasíferos regionales, influyendo en la transformación de los escenarios de integración energética.

En Argentina, el gas aporta $50 \%$ de la energía consumida en el país. La red de gas alcanza a $67 \%$ de la población argentina. Hay industrias además "gasívoras": algunas consumen gas como materia prima -por ejemplo, para producir urea- y otras para energía (generación de calor o electricidad). El gas también se utiliza considerablemente para el transporte: en el año 2009, en un parque de 7 millones de vehículos, alrededor de 1 millón y medio funcionan a GNC. Las redes argentinas de transporte y distribución de gas -de Campo Durán a Ushuaia- fueron concesionadas en 1992 a empresas privadas, fiscalizadas por el Ente Nacional Regulador del Gas (ENARGAS, Ley del Gas N² 24.076). Los gasoductos que vinculan la cuenca noroeste -y la de Cuyo- a Buenos Aires son operados por Transportadora de Gas del Norte S. A., $56 \%$ propiedad de Gasinvest S. A. (TecGas, Compañía General de Combustibles, Total Gas y Petronas), $24 \%$ de CMS Gas y un $20 \%$ negociado en la Bolsa de Comercio de Buenos Aires. Mientras el sistema de transporte fue atribuido a dos empresas, una al norte y otra al sur del país, el de distribución fue dividido en 9 áreas geográficas menores. Así el transporte en las provincias de Jujuy, Salta, Tucumán y Santiago del Estero está a cargo de la empresa Gasnor (consorcio formado por el operador chileno Gasco y José CarteIlone Construcciones Civiles) que logró una concesión de 35 años. Los grandes clientes compran directamente a los productores, aunque con dificultades crecientes, ya que se les han aplicando cortes de luz y gas en los últimos inviernos. Las estaciones de servicios de GNC compran en el mercado electrónico. Hay unas 70 estaciones de servicio de GNC en Tucumán, 35 en Salta y 20 en Jujuy. Estas provincias registran 38.000, 21.000 y 10.000 vehículos, respectivamente. Formosa registra una centena de vehículos a GNC, pero ninguna estación.

El transporte de gas en Bolivia también es operado por dos grandes empresas: Transierra y Transredes. Transierra -constituida por Petrobrás, Andina y Total- opera el GASYRG, gasoducto que va de Yacuiba a Río Grande, llevando gas tarijeño, principalmente de los campos San Alberto y San Antonio, a Santa Cruz (Figura $N^{\circ} 1$ ). Transredes -recientemente nacionalizada- posee $3.000 \mathrm{~km}$ de ductos para el transporte de hidrocarburos líquidos y $3.000 \mathrm{~km}$ de gasoductos, abasteciendo aproximadamente $37 \%$ del mercado interno y $45 \%$ del mercado de exportación (Brasil y Argentina). Transredes tiene una participación de $51 \%$ en la empresa GTB Transboliviano que conecta el sistema boliviano de Transredes con Brasil (Río Grande-Puerto Suárez). También se ocupa de vender el gas que compra a los productores, los que, hasta mayo de 2006, vendían directamente a los clientes. La distribución está a cargo de empresas locales (Decreto 28.291 de 2005) con estatuto particular en cada departamento: hay empresas públicas y privadas, y donde no hay una distribuidora interviene YPFB. Por ejemplo, en el departamento de Santa Cruz opera una compañía prácticamente privada -Sergas, conformada por socios bolivianos (46\%), CREE, una cooperativa eléctrica $(46 \%)$, YPFB $(4 \%)$ y alcaldía municipal (4\%), atendiendo esencialmente en la zona urbana y el parque industrial-; mientras que en Tarija la distribuidora es una empresa pública del departamento (Emtagas).

Cabe señalar que Sergas tiene un contrato por 20 años hasta 2009, entonces podría pasar bajo el control de YPFB que tiene derecho preferente para adquirirla. En Santa Cruz, el consumo residencial crece más lentamente que en Tarija y representa $6 \%$ de las ventas totales de Sergas. Los consumos de GNV (gas natural vehicular) significan el $30 \%$. El consumo de GNV experimentó un crecimiento rápido desde 2005, gracias a un mecanismo que permite la recuperación parcial del costo de la conversión de los vehículos a través de "cheques para GNV" equivalentes al valor de la mitad de la inversión realizada por los automovilistas. El consumo industrial es el mayor: más de $50 \%$ lo compran tres grandes aceiteras (2007). La explotación del yacimiento de hierro del Mutum -próximo a la frontera con Brasil- y que absorbería grandes volúmenes de gas, aún es proyecto.

La apertura de economías y la reconstitución de vínculos institucionales internacionales de los años 1990, dinamizaron el sector petrolero y gasífero: favorecieron la multiplicación de actores con roles diversos y las 
inversiones en conexiones entre las redes de los países del Cono Sur y el continente.

Las exportaciones de gas boliviano hacia Argentina se hacen por dos gasoductos con baja capacidad; uno antiguo desde Pocitos, y otro nuevo desde Madrejones, ambos se dirigen a Campo Durán (provincia de Salta) donde se encuentra la única refinería que Argentina posee en el norte. El primer gasoducto permitió que se inyectaran 4,2 millones de $\mathrm{m}^{3} /$ día de gas boliviano en la red argentina en 1972. El segundo fue inaugurado treinta años después, en junio de 2002, junto con la planta de tratamiento de Pluspetrol en Madrejones (Bolivia) desde donde recorre $43 \mathrm{~km}$ para llegar a la planta Campo Durán donde Refinor S. A. acondiciona el gas que luego es transportado hasta la Central Térmica Ave Fénix de Pluspetrol, ubicada en la provincia de Tucumán.

Entre Argentina y Chile, en la frontera norte, se construyeron dos gasoductos de exportación:

1. Norandino, operado por una sociedad anónima homónima controlada por Suez, que aprovisionaría las centrales de ciclo combinado ubicadas en el Sistema Interconectado del Norte Grande (SING), así como los centros mineros e industriales de la zona.

2. Atacama, operado por una empresa formada por ENDESA Chile y CMS Energy para suministrar gas natural a la II Región de Chile. Además, se tendió un electroducto argentino-chileno de Salta a Atacama 345kV - $600 \mathrm{MW}$, construido por una empresa chilena también para aprovechar el potencial gasífero argentino.

Cabe señalar que ya la ejecución de estas obras suscitó numerosos conflictos que motivaron la intervención de diversos actores y despertaron reacciones diversas en la población (Reboratti, 2003).

Por la descentralización implementada en los marcos legislativos nacionales, los gobiernos locales se ven obligados a repensar sus territorios como espacios productivos al interior de redes de mayor escala y ligados a dinámicas mundiales. En Bolivia, las tensio- nes entre el poder central y los departamentos orientales productores de hidrocarburos representan una amenaza para la unidad nacional. En Argentina, la posición de Salta aparece más frágil porque es difícil organizar un frente unido de las provincias del norte para presionar al gobierno nacional, por la dependencia financiera de muchas de ellas respecto del Estado federal.

Ni esta situación ni las dificultades en lograr inversiones y mayor producción impiden intentar avanzar en el camino de la integración en territorios fronterizos para superar dificultades y (re)crear sinergias productivas. Una manifestación de esto es el Plan Maestro de Integración y Desarrollo Fronterizo Argentina-Bolivia, actualmente en fase de elaboración bajo los auspicios de la Corporación Andina de Fomento.

\section{Nuevos escenarios de integración energética}

En los años 1990, Bolivia se proyectaba como motor energético del Cono Sur. Numerosos proyectos buscaban conectar sus cuencas a potenciales mercados regionales y externos. Actualmente Bolivia tiene como principal prioridad aprovisionar el mercado interno; la segunda es abastecer a Brasil con 30 millones de $\mathrm{m}^{3}$ /día de gas, para cumplir con el contrato take or pay que rige hasta el año 2019. En tercer lugar, Bolivia vende gas a Argentina, enviándole ahora aquello que resta: actualmente menos de 2 millones de $\mathrm{m}^{3} /$ día, cuando estaba contemplado por contrato enviar 7,7 millones de m³/día en 2008 . Argentina, a su vez, ha tenido que acotar sus ventas a Brasil, Uruguay y Chile.

Si Brasil contemplaba la posibilidad de duplicar los volúmenes de gas importados de Bolivia (construyendo otro gasoducto con capacidad para transportar 30 millones de $\mathrm{m}^{3}$ diarios), y Argentina preveía la construcción de un nuevo gasoducto del noreste que conecte la cuenca de Tarija con las regiones de Argentina que aún carecen de servicio de gas (por ejemplo, las provincias de Formosa y Misiones) y los mercados mayores, ambas opciones parecen frenadas. En este contexto cada país explora nuevas soluciones para cubrir sus necesidades. 
En Brasil, por un lado, cobran mayor legitimidad las enormes y riesgosas inversiones requeridas para el desarrollo de reservas onshore y fundamentalmente offshore (produjo 18 mil millones $\mathrm{m}^{3}$ en 2007 aunque aún quema o reinyecta la mayor parte). Por otro lado, avanzan los proyectos de importar GNL. El Conselho Nacional de Política Energética (CNPE) establece directrices y recomienda acciones para implementar proyectos de importación de GNL para el mercado brasileño "de forma de garantizar un aprovisionamiento confiable, seguro y diversificado de gas natural" (Resolución 04, 24 noviembre 2006). Los primeros proyectos se localizan en la Bahía de Guanabara (Río de Janeiro) y Pecém (Ceará).

En Argentina se contrató un barco regasificador que inyecta gas natural de cuencas distantes, en el puerto de Bahía Blanca para cubrir los picos de demanda gasífera invernal, aprovechando la contraestacionalidad hemisférica que deja disponible el buque en el verano europeo, ya que no son numerosos los buques regasificadores. Logra también proveerse de GNL, escaso y, en general, sujeto a contratos a largo plazo. La integración vertical de Repsol YPF y su inserción en el mercado del GNL facilita la operación. El buque regasificador, recargado desde otros barcos, ha inyectado, desde junio, 5 millones $\mathrm{m}^{3} / \mathrm{d}$ ía de gas proveniente de Trinidad y Tobago y Egipto. Se palia así la escasez de gas pero a un precio del orden de los 15 US\$/ MBTU contra 2 US\$MBTU y 8 US\$MBTU a los que se pagan el gas argentino y boliviano, respectivamente. Así Argentina entra en el mercado internacional del GNL en el año 2008. ENARSA estudia construir plantas regasificadoras en tierra (una en Montevideo y otra en Bahía Blanca), las que requieren contratos a largo plazo. De este modo se refuerza la elección de hacer del gas la principal fuente energética argentina.

Bolivia no aceptó inyectar su gas, vía Argentina, en Chile. Las mismas razones sociopolíticas habían impedido, en 2003, concretar un proyecto de exportar gas natural licuado por los puertos chilenos hacia la costa sur de Estados Unidos, vía México (proyecto que llevara al final anticipado del mandato de dos presidentes). Paradójicamente, desde 1958 existe un oleoducto entre Cochabamba
(Bolivia) y Arica (Chile). Paralelo, sobre esas tierras sujetas a acuerdos binacionales y de complementación económica, se ha tendido además un ferrocarril.

Entonces cuando Argentina tuvo que reducir significativamente sus exportaciones de gas natural, el norte de Chile que se había dotado de infraestructuras para usar este combustible, debe en buena medida sustituirlo con combustibles líquidos. Eso fue, por ejemplo, lo que aconteció con las centrales de ciclo combinado, que abastecían los gasoductos binacionales Norandino y Atacama, construidos para tal propósito. Si bien se han evitado cortes a las localidades chilenas de la región, como San Pedro de Atacama, las industrias debieron encontrar fuentes alternativas. Por lo mismo, Chile-que avanza con cierto éxito en la exploración de las aguas australes- construye dos plantas regasificadoras para comprar gas proveniente de la otra margen del océano Pacífico: una, en Quintero, para alimentar la región central; otra, en Mejillones, para el aprovisionamiento del norte. Mientras en la UNASUR (Unión de las Naciones Suramericanas) se evalúa el proyecto de tender un gasoducto a Chile desde Perú. En este país, varias empresas -entre otras, Shell que dejó Bolivia- mostraron interés por invertir en la planta de liquefacción de gas para vender a mercados distantes y en termoeléctricas, para mercado interno y para exportar electricidad a las minas de Chile y a Ecuador.

\section{Consideraciones finales}

En el noroeste argentino y sur boliviano, con ubicación estratégica para servir el norte chileno o el sur brasileño, empresas transnacionales se han instalado, desde antaño, a ambos lados de la frontera. En la región, las integraciones petrolera y gasífera se inician a comienzos de la primera y segunda mitad del siglo XX, respectivamente. Su evolución y la de actividad hidrocarburífera se vieron condicionadas, en buena medida, por los vaivenes de las políticas nacionales que a lo largo de un siglo atravesaran momentos de apertura y apoyo a la participación de las empresas extranjeras y tiempos en los que se buscó acotar el poder de las mismas. En Bolivia, esto llegó a traducirse en tres nacionalizaciones de los recursos y de la actividad. 
Con la apertura económica de finales del siglo, aparece en América Latina una nueva serie de proyectos energéticos regionales, que no respondieron a visiones de conjunto a largo plazo (Sennes y Pedroti, 2008). En el Cono Sur, tuvo lugar un proceso de integración hegemónica (Zárate et al., 2000) conducido por las grandes empresas del sector de hidrocarburos, con el aval de los Estados. En la región norte de Argentina y Chile se tradujo en la materialización de dos gasoductos y un electroducto, apuntando a crear una sinergia productiva entre la puesta en valor de los recursos gasíferos argentinos y el desarrollo de actividades "energívoras" chilenas. Pero con la disminución de los flujos energéticos al interior del Cono Sur, esta complementación se vio restringida o interrumpida.

Entre Argentina y Bolivia, los nuevos grandes proyectos de interconexión, como el gasoducto del noreste, se lanzaron más tarde, cuando las tendencias integracionistas en la región estaban cambiando. Por una parte, la apertura y la desregulación eran revisadas suscitando entre los inversores desconfianza institucional e inseguridad jurídica-. Por otra parte, la sostenibilidad del funcionamiento del sistema energético era ampliamente cuestionada ante la escasez de reposición de reservas, la insuficiencia en producción y lo limitado de la capacidad de transporte. Así es que del lado argentino persisten incertidumbres en relación con la licitación del gasoducto del noreste o la ampliación del gasoducto del norte; mientras que del lado boliviano, si bien ratifican la decisión de concluir en el año 2013 un gasoducto hasta la frontera para enviar a Argentina más de 20 millones de $\mathrm{m}^{3} /$ día, la capacidad de producción boliviana no parece en medida de alcanzar esta meta.

En la década de 1990, Argentina y Bolivia eran vistos como posibles motores del Cono Sur y exportadores a mercados distantes. Pero la dinámica energética regional difiere de lo proyectado entonces. La flexibilidad y rapidez con que reaccionan las empresas, emprendiendo o suspendiendo actividades, asociadas y dividiendo riesgos, facilitó ese giro en el siglo XXI. Ahora el freno en los proyectos de conexión y en los flujos entre Argentina y Bolivia repercute en los intercambios energéticos del conjunto de países del Cono Sur, complicando nuevamente el proceso de integración, lento y reiteradas veces promovido. Luego cada Estado nacional busca diversificar las fuentes de aprovisionamiento, incluso en mercados distantes. De esa forma, se ha invertido la tendencia centrífuga de exportar hidrocarburos desde Bolivia y Argentina, hacia una suerte de movimiento centrípeto que tiende a multiplicar proyectos y flujos de importaciones hacia el Cono Sur.

En esta evolución de la oferta energética se han fragilizado las oportunidades argentinas y bolivianas de desarrollar reservas y mercados de hidrocarburos; se han creado o agudizado conflictos entre los actores y las sociedades involucradas; así como también se han restringido las posibilidades de desarrollo regional. En ese sentido, ha aumentado la vulnerabilidad de los territorios con efectos desestabilizadores desde el punto de vista social y económico, los que se suman a los conflictos de una región con altos índices de pobreza y marginalidad, ya golpeada por las reestructuraciones de las empresas del Estado.

En los últimos años, buscando el paso de una lógica de explotación nacional de los recursos hidrocarburíferos a una de valorización complementaria de los recursos naturales (Carrizo \& Velut, 2005), se multiplicaron los lazos entre poderes públicos locales y privados. Los gobiernos locales, también obligados por la descentralización implementada, refuerzan sus relaciones y posiciones en el sector del petróleo y el gas, dominado por empresas con estrategias regionales y globales. Al mismo tiempo también multiplican sus vínculos con una constelación creciente de actores que reaccionan e intervienen frente a los cambios o necesidades que se plantean.

De este modo, en los territorios se han ido modificando los mecanismos clásicamente liderados por los Estados nacionales. Del lado boliviano, se manifiestan actualmente tendencias autonomistas en los departamentos de Tarija y Santa Cruz, con la voluntad de un mayor control sobre sus recursos en hidrocarburos. Del lado argentino, la provincia de Salta desarrolla una estrategia de la oferta a través de la construcción de gasoductos para estimular la producción. En ambos casos, la convergencia de los intereses regionales con 
el sector privado transnacional tiene aristas jurídicas, políticas y económicas de trascendencia no solo local sino también nacional e internacional a conciliar-si no disputar-con otras provincias y Estados.

Entre el noroeste de Argentina, el sur de Bolivia y el norte de Chile, un territorio con fronteras históricamente permeadas por una integración diversificada y compleja, las redes de hidrocarburos avanzan en un juego histórico entre poderes públicos nacionales, gobiernos locales e influyentes actores privados. La profundización del estudio del noroeste argentino y sur boliviano refuerza la convicción de que se trata de una región con gran potencial, cuyo mejor conocimiento podría propiciar la identificación de caminos sostenibles frente a las recomposiciones territoriales que pueden resultar de los conflictos actuales.

\section{Referencias bibliográficas}

CARRIZO, S. \& VELUT, S. Nouvelles territorialités en Amérique australe. Activités energetiques et intégration dans les terres et mers Magallanes. Espace géographique, 2005, N ${ }^{\circ} 2$, p. 161-175.

CONSELHO NACIONAL DE POLÍTICA ENERGÉTICA. Resolução $N^{\circ} 4$, de 21 de novembro de 2006. Brasilia: Ministério de Minas e Energia, 2006. Disponible en Internet: http://www.mme.gov.br/mme/galerias/arquivos/conselhos_comite/CNPE/resolucao_2006/ Resolucao04.pdf

CROZET, Y. \& MUSSO, P. (dir.). Réseaux, services et territoires. Horizon 2020. Paris: Editions de l'Aube / Datar, 2003.
DUPUY, G. Réseaux territoriaux. Transport \& communication. 14. Caen: Ed. Paradigme, 1988.

GADANO, N. Historia del petróleo en la Argentina. 1907-1955: desde los inicios hasta la caída de Perón. Buenos Aires: Edhasa, 2006.

LAGOS, R. (comp.). América Latina: ¿integración o fragmentación? Buenos Aires: Edhasa, 2008.

REBORATTI, C. Los gasoductos del Norte. Ciencia Hoy, 2003, vol. 13, № 77, p. 20-31.

SCHEER, H. L'autonomie énergétique. Une nouvelle politique pour les énergies renouvelables. Arles: Actes Sud, 2007.

SENNES, R. y PEDROTI, P. Entre la geopolítica y la geoeconomía: la energía. En: LAGOS, R. (comp.). América Latina: ¿integración o fragmentación? Buenos Aires: Edhasa, 2008, p. 527-567.

SOLBERG, C. Oil and Nationalism in Argentina. A history. California: Standford University Press, 1979.

YACIMIENTOS PETROLÍFEROS FISCALES (YPF). La exploración de petróleo y gas en la Argentina: el aporte de YPF. Buenos Aires: YPF, 2000.

ZÁRATE, R.; ARTESI, L.; MARTINEZ LLANEZA, D.; BUZZI, M. y SALAZAR, A. Patagonia austral. Integración inconclusa y subdesarrollo inducido. Rosario: Homo Sapiens, 2000. 